\title{
Analysis on Fracture Behavior and Optimization of Beam-Column Connections with Expanded Flanges of Steel Frames
}

\author{
Hongwei Ma, ${ }^{1,2}$ Zhen Zhang, ${ }^{1}$ Kun Wang $\mathbb{D}^{1,3}$ Yan Liu, ${ }^{1}$ Kai Guo, ${ }^{4}$ and Fuzhang Wang ${ }^{2}$ \\ ${ }^{1}$ College of Civil Science and Engineering, Yangzhou University, Yangzhou 225127, China \\ ${ }^{2}$ School of Mathematical Science, Huaibei Normal University, Huaibei 235000, China \\ ${ }^{3}$ Jiangsu Hanjian Group Company Limited, Yangzhou 225000, China \\ ${ }^{4}$ College of Guangling, Yangzhou University, Yangzhou 225127, China \\ Correspondence should be addressed to Kun Wang; wangkun@yzu.edu.cn
}

Received 28 March 2020; Revised 8 September 2020; Accepted 18 September 2020; Published 1 October 2020

Academic Editor: Raffaele Landolfo

Copyright ( $\odot 2020$ Hongwei Ma et al. This is an open access article distributed under the Creative Commons Attribution License, which permits unrestricted use, distribution, and reproduction in any medium, provided the original work is properly cited.

\begin{abstract}
In this study, the parameters of concave expanded flanges of beam-column connections of steel frames are optimized based on the effects of different sizes of concave expanded flanges on the fracture performance. Firstly, two beam-column connection models with concave expanded flanges are built and analyzed under cyclic loads, which have the same conditions as the specimens during the previous test. Secondly, the validity of the numerical simulation models is verified through analyzing the hysteretic behaviors of the connections with concave expanded flanges, such as the plastic hinge position, the hysteresis curves, the skeleton curves, the stiffness degradation, the ductility coefficient, and the energy dissipation capacity. Thirdly, in order to comprehensively evaluate the fracture status of metal materials, the relevant fracture evaluation index (the stress triaxiality ratio $\left(R_{\sigma}\right)$, plastic equivalent strain index (PI), and cracking index (RI)) are introduced. Afterwards, eighteen numerical simulation models with differences in the length $l_{a}$ of the reinforced section, the length $l_{b}$ of the transition section, and the width $c$ of the reinforced section were analyzed. Finally, the parameters of the concave expanded flanges of the beam-column connections are optimized based on the results of the three fracture evaluation index.
\end{abstract}

\section{Introduction}

The welded steel beam-column moment-resisting connections of steel frames caused widespread damage during the Northridge earthquake in the United States in 1994 and the Kobe earthquake in Japan in 1995, which shows that the design of conventional beam-column connections welded in steel frames has difficulty in meeting the requirements of the standards $[1,2]$. In the past design concept, the plastic hinge can be ensured in the beam of the steel beam-column connections based on the ductility of the material under a strong earthquake. And the earthquake energy is dissipated through the formation and rotational of the plastic zone in order to guarantee the integrity of the structure. However, the design idea of "strong column weak beam, strong joint weak component" [3] was not realized in these two earthquakes. In order to avoid the brittle fracture of steel beam- column connections, the most effective way is currently to move the plastic hinge away from the beam end by reinforcing or reducing the beam section (RBS) [4].

As for beam-column connections with reduced beam section, numerous studies on the mechanical performance of dog-bone connections have been carried out through test and numerical simulation by Pachoumis et al. [5], Pachoumis et al. [6], Swati and Gaurang [7], Oh et al. [8], Wang et al. [9], Soliman et al. [10], Zhang et al. [11], and Nia and Moradi [12]. The preselected reducing region on the beam can quickly enter the plastic state in order to achieve moving out plastic hinge. However, the studies on beamcolumn connections with reinforced beam flanges are relatively less (Lu et al. [13], Wang et al. [14], Yang and Chen [15], Wang et al. [16], Tian et al. [17], and Ma et al. [18]), which was adopted by the Chinese code [19]. In addition, most of them were focused on the mechanical performance 
of the connections themselves without considering the effects of different sizes of reinforced beam flange on the fracture properties of the connections.

In previous research work, the beam-column connections with concave expanded flanges have better mechanical performance than that of the connections with convex expanded flanges by analyzing the experimental hysteretic behaviors of five full-scale steel beam-column connection specimens (four had expanded beam flanges with different arc shapes, lengths, and widths and the fifth was a control specimen without expanded beam flange) under cyclic loading. Based on the results, two numerical simulation models of the beam-column connections with concave expanded flanges are established and analyzed, wherein the conditions are the same as those used in the test. Afterwards, the validity of the numerical models is verified through comparing the hysteretic behaviors obtained from the test and numerical simulation. According to the fracture index, the parameters of the concave expanded flange (the length of the line $\left(l_{a}\right)$, the length of the $\operatorname{arc}\left(l_{b}\right)$, and the width $\left.(c)\right)$ of the connections are optimized by analyzing the stress triaxiality ratio $\left(R_{\sigma}\right)$ [20], plastic equivalent strain index (PI) [21], and cracking index (RI) [22].

\section{Numerical Modeling}

In previous research work $[18,23]$, the mechanical performance of the beam-column connections with expanded flanges of concave arc has more advantages than that of the connections with expanded flanges of convex arc by analyzing the hysteretic behavior, so the beam-column connections with expanded flanges of the concave arc are the study object in this paper. Afterwards, the connections are simulated in ABAQUS [24, 25], whose validity will be verified by comparing with the hysteretic behaviors of the test and numerical simulation, so wherein the conditions are the same as those used in the test. Furthermore, the verification of these models lays a foundation for the later fracture index analysis.

2.1. Design of the Connections with the Concave Expanded Flanges. In order to verify the validity of the finite element models of beam-column connections by comparing hysteretic behavior between the test and numerical simulation, two connection specimens with a concave arc in the expanded flanges (WF-1A, WF-1B) are designed, which have different lengths of the reinforced section and the transition section of the expanded flanges. And the dimensions of the connections are the same as that in the test, the details of the specimens are shown in Figure 1, and the model parameters are shown in Table 1.

2.2. Material Properties. The constitutive relation diagram of steel Q235B and weld E4315, which adopt threefold line models, is shown in Figure 2. The material parameters of steel and weld are obtained through material testing $[17,23]$ : $f_{y}=287.3 \mathrm{~N} / \mathrm{mm}^{2}, \varepsilon_{y}=0.14 \%$, EQ235 $=2.06 \times 105 \mathrm{~N} / \mathrm{mm}, f_{u}=$ $393.1 \mathrm{~N} / \mathrm{mm}^{2}, \varepsilon_{u}=11.7 \%, f_{s t}=348.11 \mathrm{~N} / \mathrm{mm}^{2}, \varepsilon_{s t}=18.47 \%$, and $\quad v=0.3 ; f_{y}=330 \mathrm{~N} / \mathrm{mm}^{2}, \quad \varepsilon_{y}=0.16 \%, \quad \mathrm{EE} 4315=2.05$ $\times 105 \mathrm{~N} / \mathrm{mm}, f_{u}=420 \mathrm{~N} / \mathrm{mm}^{2}, \varepsilon_{u}=22 \%$, and $v=0.3$, respectively. In the numerical simulation model, the geometric nonlinearity, the material nonlinearity, and the Bauschinger effect [24] are taken into consideration, but the effects of the welding defects and welding residual stresses in the beamcolumn connections are not considered because of a shortage of test data.

2.3. Mesh and Boundary Conditions. According to the characteristics of the beam-column connections with concave expanded flanges, the eight-node hexahedral linear reduction integral unit (C3D8R) is suitable for meshing these two numerical simulation models of the connections because of the advantages of computation time and distortion resistance [26]. Based on the sensitivity optimization analysis [27], in the finite element models, the different positions of the specimen should be meshed separately, the mesh size of the upper part of the beam is 24 , and the mesh size of the expanded beam end and the weld is 12 . The mesh size of both ends of the column is 50 , and the mesh size of the middle part of the column is 25 ; meanwhile, the mesh size of the web stiffener of size is 25 . Hereafter, the meshed beamcolumn connection is shown in Figure 1(b). About boundary conditions of the numerical simulation models, the displacements in the $X, Y$, and $Z$ directions are imposed on both ends of the column, and the boundary conditions of the model are shown in Figure 3. As for the loading section at the end of the beam, the $Y$-displacement is imposed at the center of the section, whose all nodes in this section are coupled in the $Y$-direction. The loading conditions are the same as those used in the experiment.

\section{Hysteretic Behavior}

3.1. Plastic Hinge Position. Figure 4 presents a comparison of the deformation of two connection specimens with concave expanded flanges between the test and numerical simulation under $250 \mathrm{~mm}$. The plastic hinge position of the numerical simulation models is basically consistent with that of the test results. The beam flange of the beam with the $100 \mathrm{~mm}$-length of the reinforced section, which is in the range of $100 \mathrm{~mm}-350 \mathrm{~mm}$ from the beam end, has a large plastic buckling deformation, and the beam web also has a slight buckling, but the buckling range of the numerical model is less than that of the experimental results because of the existence of stress concentration of weld. Furthermore, the buckling range of the beam flange of the beam with the $200 \mathrm{~mm}$ length of the reinforced section is $350-400 \mathrm{~mm}$ from the beam end, which indicates that increasing the length of the expansion is beneficial for moving the plastic hinge away from the beam end. Meanwhile, the buckling range of the numerical model is also less than that of the experimental results.

3.2. Hysteresis Curve. A comparison of the 2 hysteresis curves of the connection specimens with concave expanded flanges between the test and numerical simulation 


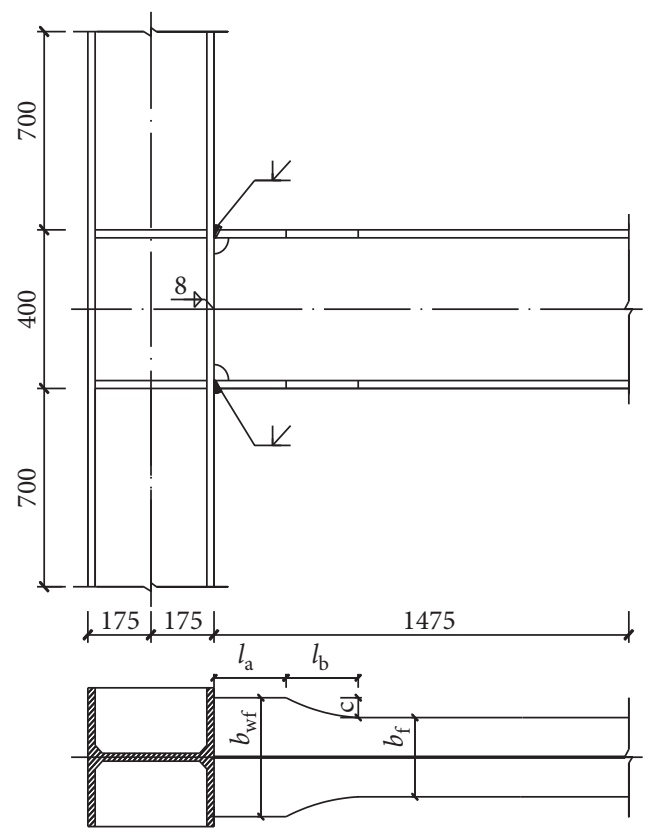

(a)

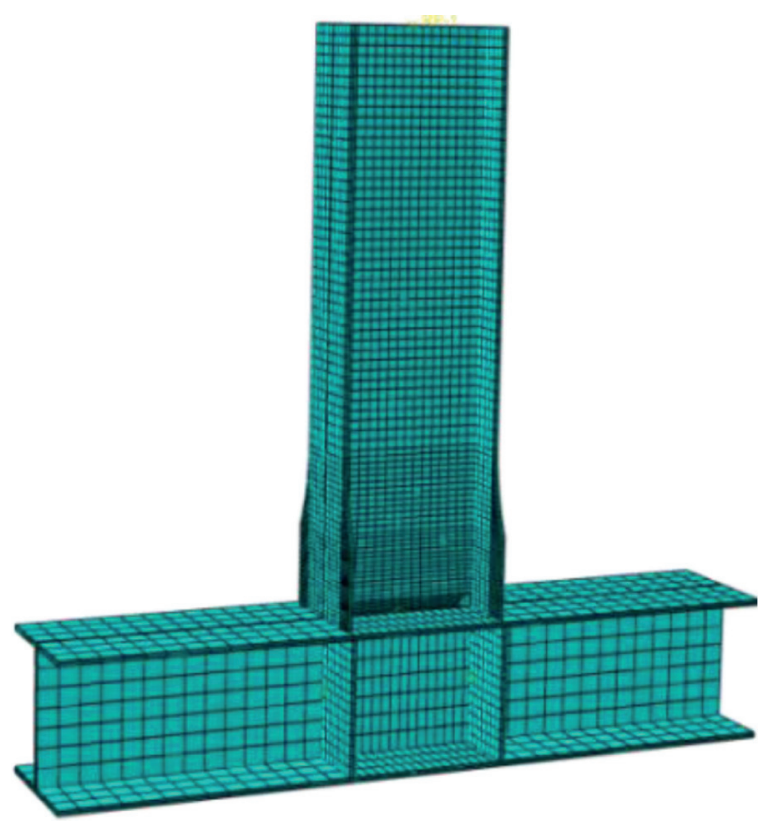

(b)

Figure 1: Details of specimens. (a) WF-1. (b) Finite element model.

TABLE 1: Specimen parameters.

\begin{tabular}{lcccc}
\hline Specimens & Expansion & Length of line $\left(l_{a}\right)(\mathrm{mm})$ & Length of $\operatorname{arc}\left(l_{b}\right)(\mathrm{mm})$ & Width $(c)(\mathrm{mm})$ \\
\hline WF-1A & Concave-arc & 100 & 100 & 40 \\
WF-1B & Concave-arc & 200 & 200 & 50 \\
\hline
\end{tabular}

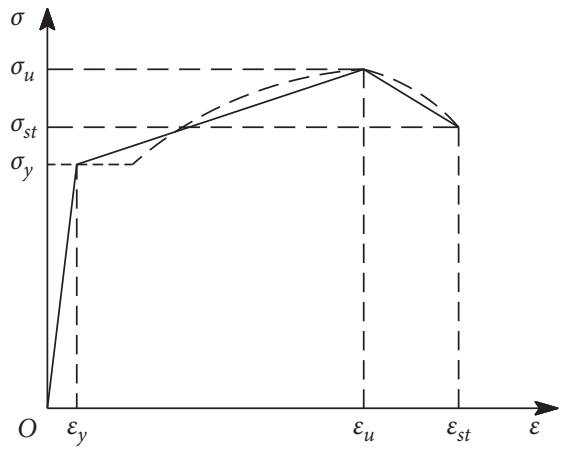

(a)

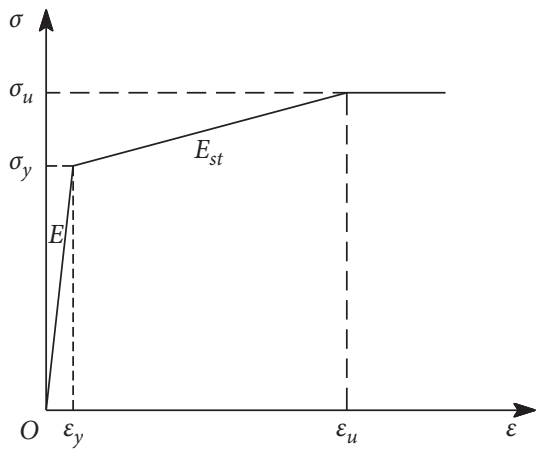

(b)

FIGURE 2: Material constitutive model. (a) Q235B steel. (b) E4315 weld.

is shown in Figure 5. The shapes of the hysteresis curves from the finite element calculation and the test are basically the same, which exhibit spindle shapes. And the values in the FE results are slightly larger than those in the test because of the existence of material defects and manufacturing errors. Meanwhile, rheostriction is observed in the middle of the test curves. The ultimate values for the WF-1B are larger than those of the WF-1A, and the energy dissipations are faster than those of the WF-1A, which indicates that increasing the length of the expansion is beneficial to improving the ultimate bearing capacity of the connections with concave expanded flanges, but it is not conducive to the overall energy dissipation.

3.3. Skeleton Curve and Stiffness Degradation Curve. From the skeleton curves of the connection specimens with concave expanded flanges between the test and numerical simulation, which is in Figure 6, in general, the values of the finite element models are larger than those of the test, which is consistent with the hysteretic 


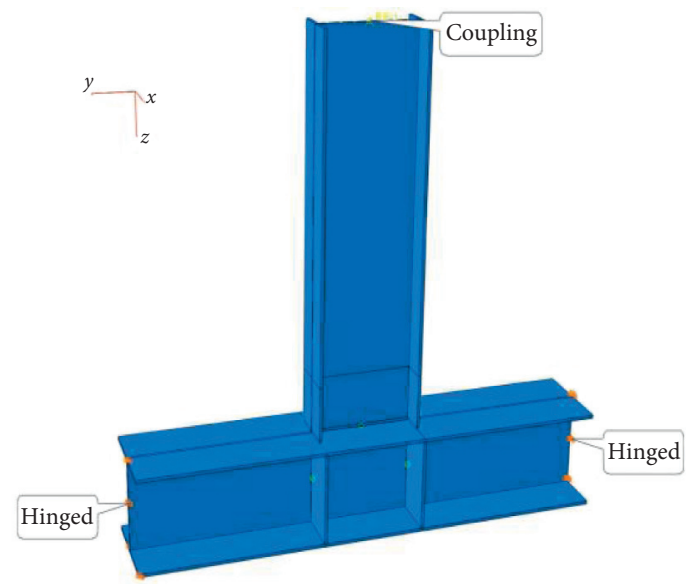

Figure 3: Boundary conditions of the finite element model.
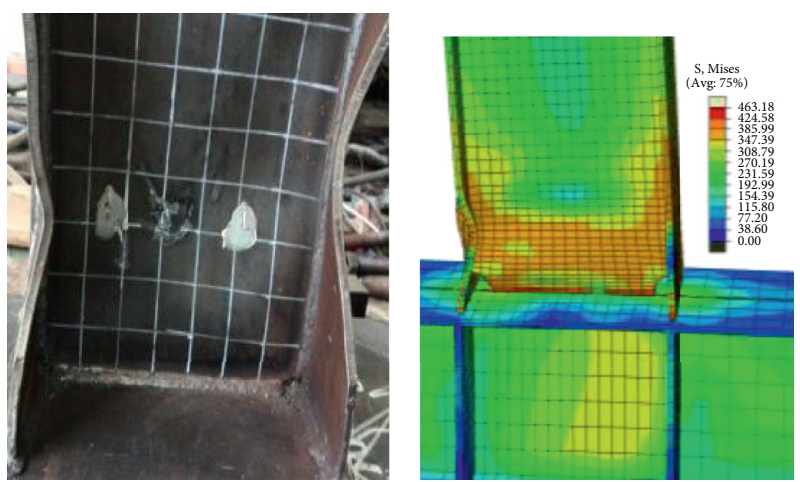

(a)
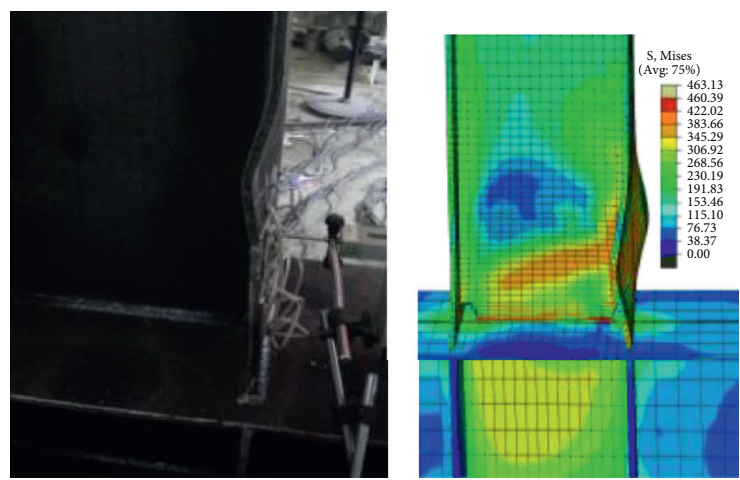

(b)

FIgURe 4: Position of plastic hinge. (a) WF-1A and (b) WF-1B.

curves. Meanwhile, the deformation of the WF-1A is less than that of the WF-1B. Furthermore, the skeleton curves of each specimen before the yield are linear; it will become nonlinear after the yield, and the curves decline slowly after reaching the ultimate load. As for the ultimate load, the experimental ultimate load of the WF-1A is $312.86 \mathrm{kN}$ and the numerical ultimate load of the WF$1 \mathrm{~A}$ is $335.45 \mathrm{kN}$. Meanwhile, the experimental ultimate load of the WF-1B is $337.71 \mathrm{kN}$, and the numerical ultimate load of the WF-1B is $354.37 \mathrm{kN}$. From the above data, the value of the WF-1 is obviously less than that of the WF-2, which indicates that the increase of the length of the expansion of the beam-column connection can increase the bearing capacity of the connection. Meanwhile, the value of the numerical simulation is higher than that of the test because the materials in the numerical model are ideal.

The 2 stiffness degradation curves from the test and numerical simulation are shown in Figure 7 . The trend of the stiffness degradation coefficients $\beta$ of each model is basically similar, and the error of the stiffness degradation coefficients $\beta$ is small, which shows that the change of the length of the expanded flange has little effect on the $\beta$ value.
3.4. Ductility Coefficient and Energy Dissipation Coefficient. The ductility coefficient $\mu$ and energy dissipation coefficient $E_{h}$ for the 2 models with concave expanded flanges are shown in Table 2. In terms of $\mu$, the ductility coefficients of the WF-1A are higher than those of the WF-1B, which indicates that the ductility decreases with the increase of the length of the expansion of the connection. Meanwhile, the energy dissipation coefficients Eh of the WF-1A are also higher than those of the WF-1B, which shows that the energy dissipation slightly decreases with the increase of the length of the expansion.

From the above analysis about hysteretic behavior of the test and numerical simulation, the method of establishing the numerical models is reasonable because the trend of the numerical simulation is basically the same as that of the test, and the error between the two results can be accepted, so the method can be used to optimize the parameters of the expansion next. Meanwhile, the optimal range of the expansion can be obtained by comparing the fracture performance because the weld plays an important role in the mechanical performance of the beam-column connections.

3.5. Optimization of the Connections with Concave Expanded Flanges. If the beam-column connections with concave expanded flanges are to avoid fracture resistance under 


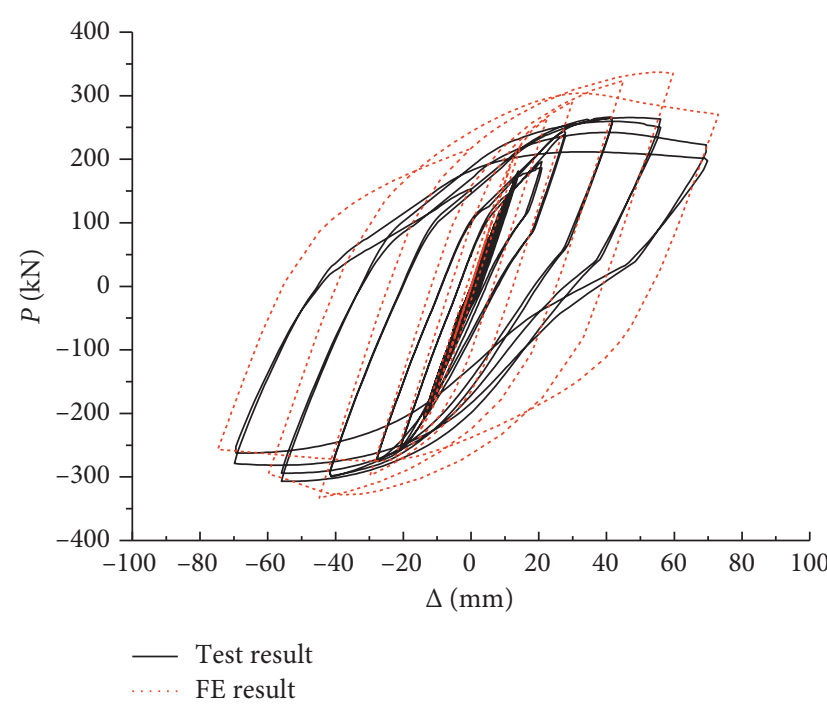

(a)

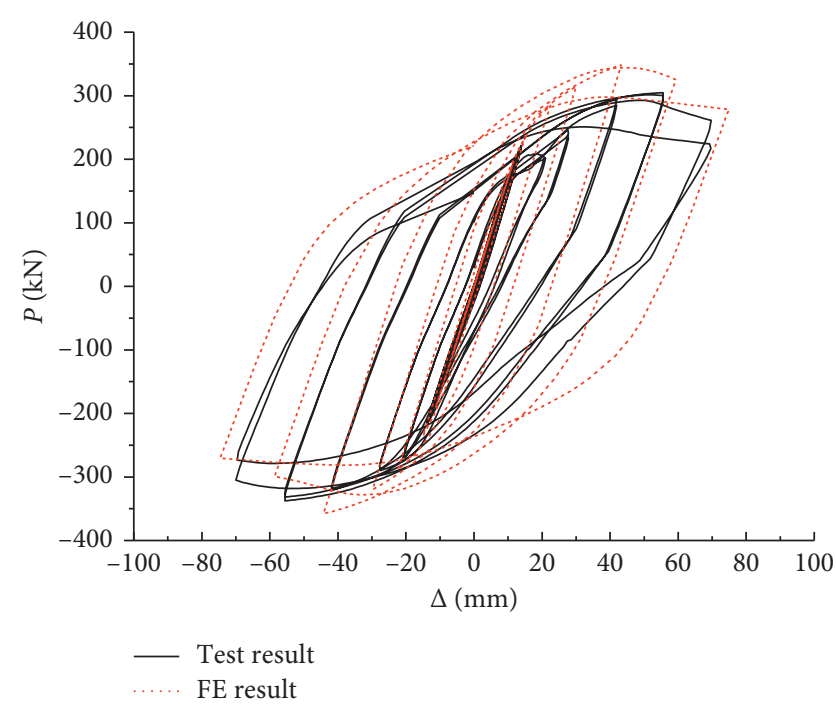

(b)

Figure 5: Hysteretic curves. (a) WF-1A. (b) WF-1B.

earthquake loads, it is also necessary to study brittle fractures of the connections. In order to evaluate the effect of different parameters of the expansion on the fracture performance, three groups of numerical simulation models (WF-A, WF-B, and WF-C) are established in ABAQUS, which are different in the length $l_{a}$ of the reinforced section, the length $l_{b}$ of the transition section, and the width $c$ of the reinforced section. The basic criteria for the optimal design can be found in [28]. Path 1 for the weld is chosen, as shown in Figure 8.

In damage mechanics, the relevant fracture evaluation indexes are introduced to comprehensively evaluate the fracture status of metal materials [29]. Ghobadi et al. [30] adopted the stress triaxiality ratio $\left(R_{\sigma}\right)$, equivalent plastic strain index (PI), and cracking index (RI) to predict the possibility of material cracking. This method does not need to set the cracking point in advance on the base material and can be obtained directly through finite element analysis without tedious calculations. The following three evaluation indicators are described in detail.

\subsection{Fracture Evaluation Indexes}

3.6.1. Stress Triaxiality Ratio $R_{\sigma}$. The macroscopic fracture failure of materials is mainly determined by the combination of stress states at each point and in each direction. Zhu [31] from Xi'an University of Technology confirmed that the stress triaxiality ratio can effectively describe the relationship between the triaxial tension and plastic deformation at a point, and the value of this parameter is equal to the ratio between the hydrostatic pressure and equivalent pressure. The specific calculation is as follows:

$$
\begin{aligned}
& R_{\sigma}=\frac{\sigma_{m}}{\sigma_{e}} \\
& \sigma_{m}=\frac{\left(\sigma_{1}+\sigma_{2}+\sigma_{3}\right)}{3} \\
& \sigma_{e}=\frac{1}{\sqrt{2}} \sqrt{\left(\sigma_{1}-\sigma_{2}\right)^{2}+\left(\sigma_{2}-\sigma_{3}\right)^{2}+\left(\sigma_{1}-\sigma_{3}\right)^{2}},
\end{aligned}
$$

where ${ }_{\sigma}^{m}$ is the hydrostatic pressure and ${ }_{\varepsilon}^{e}$ is the equivalent stress.

The stress triaxiality ratio has an important influence on the shape of the holes in microcosmic materials and determines the generation and development of cracks. The larger the $R_{\sigma}$ value is, the larger the volumetric deformation is, the greater the stress concentration is, the more elastic strain energy released is, and the easier cracking occurs. The literature [32] notes that, under these conditions, the possibility of brittle cracking of the material increases significantly, and the material is basically in the state of brittle fracture. The negative value represents a compressive stress field, where ductile cracking tends to occur.

3.6.2. Equivalent Plastic Strain Index PI. The material on the surface of the plastic development directly determines the internal development state of microcracks, and the equivalent plastic strain index and the crack development status are positively correlated. EI-Tawil [33] proposed the equivalent plastic strain index, which is equal to the ratio between the equivalent plastic strain and the yield strain, as shown in the following equations: 


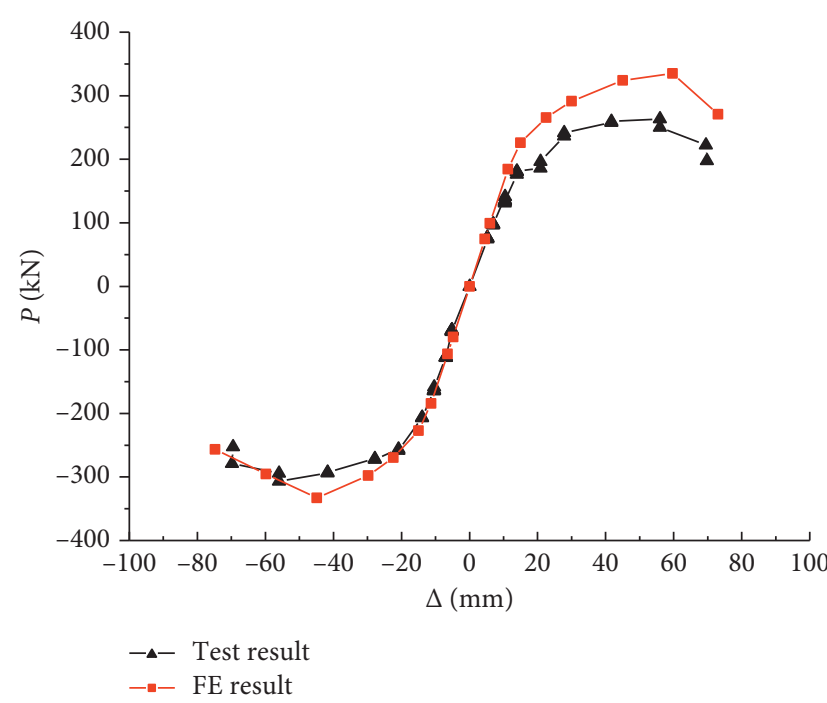

(a)

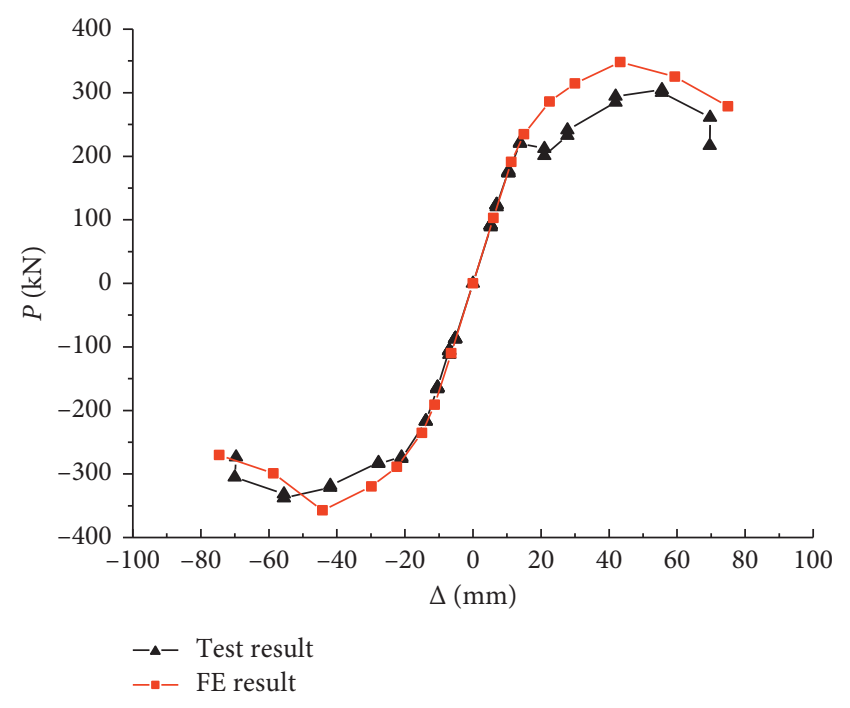

(b)

Figure 6: Skeleton curves. (a) WF-1A. (b) WF-1B.

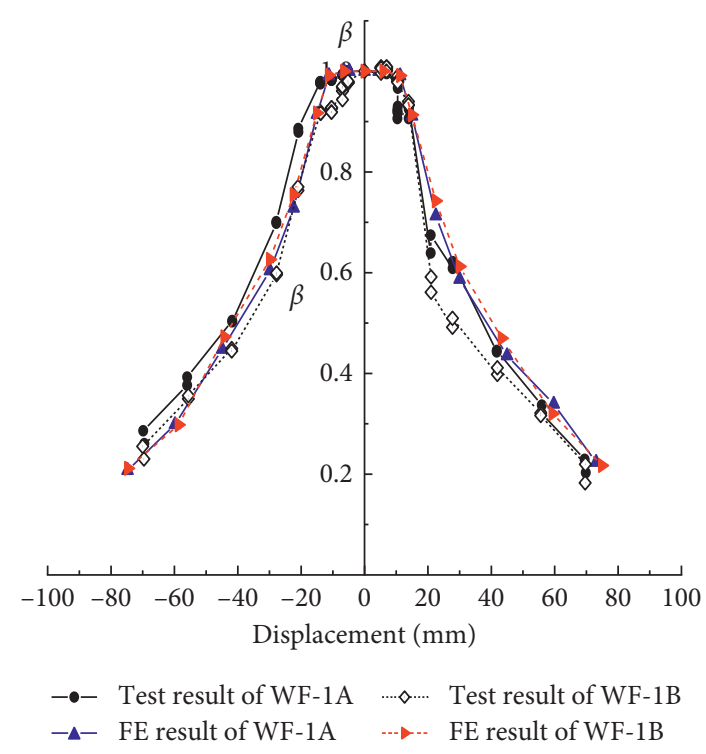

FIgURE 7: Stiffness degradation curve of WF-1.

TABle 2: Ductility coefficient $\mu$ and energy dissipation coefficient $E_{h}$.

\begin{tabular}{lccc}
\hline Parameter & Test/FE & WF-1A & WF-1B \\
\hline \multirow{2}{*}{$\mu$} & Test & 3.46 & 3.22 \\
& FE & 4.87 & 3.50 \\
\hline \multirow{2}{*}{$E_{h}$} & Test & 3.10 & 2.82 \\
& FE & 3.26 & 2.95 \\
\hline
\end{tabular}

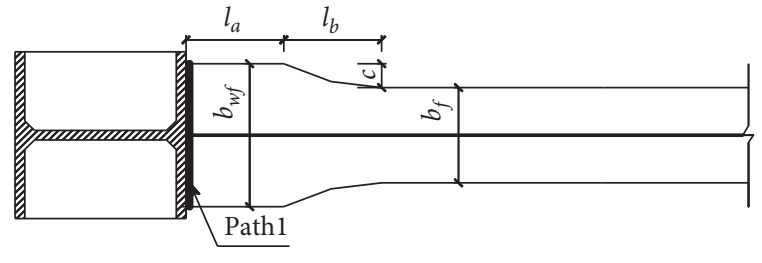

FIgURE 8: Path 1.

$$
\begin{aligned}
\mathrm{PI} & =\frac{\varepsilon_{\mathrm{eq}}^{\mathrm{pl}}}{\varepsilon_{y}}, \\
\varepsilon_{\mathrm{eq}}^{\mathrm{pl}} & =\frac{\sqrt{2}}{3} \sqrt{\left(\varepsilon_{1}^{\mathrm{pl}}-\varepsilon_{2}^{\mathrm{pl}}\right)^{2}+\left(\varepsilon_{2}^{\mathrm{pl}}-\varepsilon_{3}^{\mathrm{pl}}\right)^{2}+\left(\varepsilon_{1}^{\mathrm{pl}}-\varepsilon_{3}^{\mathrm{pl}}\right)^{2}},
\end{aligned}
$$

where ${ }_{\varepsilon}^{y}$ is the yield strain at the calculation point, $\varepsilon_{\mathrm{eq}}^{\mathrm{pl}}$ is the equivalent plastic strain, and $\varepsilon_{1}^{\mathrm{pl}}, \varepsilon_{2}^{\mathrm{pl}}$, and $\varepsilon_{3}^{\mathrm{pl}}$ shape the main strain at the current point.

The PI value can directly reflect the ductility and fracture tendency of the material. The larger the PI value, the greater the plastic deformation at the point, and the greater the possibility of ductile cracking of the material.

3.6.3. Cracking Index RI. When the stress triaxiality ratio at a certain point is high, the microcracks at that point will develop rapidly and accumulate until forming macroscopic cracks. The process from microcrack accumulation to local crack generation is the ductile cracking process of the metal material. Hancock and 
TABLE 3: Size of WF-A.

\begin{tabular}{|c|c|c|c|c|c|c|c|}
\hline \multicolumn{2}{|c|}{ Specimens } & \multirow{2}{*}{$\begin{array}{c}l_{a}(\mathrm{~mm}) \\
100\end{array}$} & \multirow{2}{*}{$\begin{array}{l}l_{a} / b_{f} \\
0.50\end{array}$} & \multirow{2}{*}{$\begin{array}{c}l_{b}(\mathrm{~mm}) \\
100\end{array}$} & \multirow{2}{*}{$\begin{array}{l}l_{b} / h_{f} \\
0.25\end{array}$} & \multirow{2}{*}{$\frac{c(\mathrm{~mm})}{50}$} & \multirow{2}{*}{$\begin{array}{l}c / b_{f} \\
0.25\end{array}$} \\
\hline \multirow{6}{*}{ WF-A } & WF-A1 & & & & & & \\
\hline & WF-A2 & 120 & 0.60 & 100 & 0.25 & 50 & 0.25 \\
\hline & WF-A3 & 140 & 0.70 & 100 & 0.25 & 50 & 0.25 \\
\hline & WF-A4 & 160 & 0.80 & 100 & 0.25 & 50 & 0.25 \\
\hline & WF-A5 & 180 & 0.90 & 100 & 0.25 & 50 & 0.25 \\
\hline & WF-A6 & 200 & 1.00 & 100 & 0.25 & 50 & 0.25 \\
\hline \multirow{6}{*}{ WF-B } & WF-B1 & 100 & 0.50 & 100 & 0.25 & 50 & 0.25 \\
\hline & WF-B2 & 100 & 0.50 & 120 & 0.30 & 50 & 0.25 \\
\hline & WF-B3 & 100 & 0.50 & 140 & 0.35 & 50 & 0.25 \\
\hline & WF-B4 & 100 & 0.50 & 160 & 0.40 & 50 & 0.25 \\
\hline & WF-B5 & 100 & 0.50 & 180 & 0.45 & 50 & 0.25 \\
\hline & WF-B6 & 100 & 0.50 & 200 & 0.50 & 50 & 0.25 \\
\hline \multirow{6}{*}{ WF-C } & WF-C1 & 100 & 0.50 & 100 & 0.25 & 25 & 0.125 \\
\hline & WF-C2 & 100 & 0.50 & 100 & 0.25 & 30 & 0.15 \\
\hline & WF-C3 & 100 & 0.50 & 100 & 0.25 & 35 & 0.175 \\
\hline & WF-C4 & 100 & 0.50 & 100 & 0.25 & 40 & 0.20 \\
\hline & WF-C5 & 100 & 0.50 & 100 & 0.25 & 45 & 0.225 \\
\hline & WF-C6 & 100 & 0.50 & 100 & 0.25 & 50 & 0.25 \\
\hline
\end{tabular}

Mackenzie [34] proposed using the stress triaxiality ratio $R_{\sigma}$ and the equivalent plastic strain index PI to define the cracking index RI when studying the brittle fracture of metal materials. The cracking index is equal to the ratio between the average stress and the equivalent stress. The calculation formula is as follows:

$$
\mathrm{RI}=\frac{\varepsilon_{\mathrm{eq}}^{\mathrm{pl}} / \varepsilon_{y}}{e^{-\left(1.5 \sigma_{m}\right) / \sigma_{e}}}=\mathrm{PI} \cdot e^{1.5 R_{\sigma}} .
$$

The cracking index can accurately describe the risk index of fracture at a certain point. The higher the RI value, the greater the possibility of cracking, and the larger the joint damage.

3.6.4. Finite Element Analysis Model. Based on the results of the above test and numerical simulation, the parameters of the expansion of the WF are consistent with those of the above numerical models. In order to investigate the effect of different sizes of concave expanded flanges on the fracture performance of the connections, the range of the parameters of the expansion of WF is selected: the length of the reinforced section $l_{a}=(0.50-1.00) b_{f}$, the length of the transition section $l_{b}=(0.25-0.50) h_{b}$, the width of the reinforced section $c=(0.125-0.25) b_{f}$, where $h_{b}$ is the height of the section of the beam and $b_{f}$ is the width of the beam. The numerical models are divided into three group models (WF-A, WF-B, and WF-C) in accordance with the three indexes of $l_{a}, l_{b}$, and $c$. Every index of the expansion of each group of models had six different parameters, which are shown in Table 3.

3.6.5. Influence of $l_{a}$. In order to study the effect of $l_{a}$ on the fracture behavior of beam-column connections with concave expanded flanges, six numerical simulation models of WF-A are designed and analyzed, whose elastic-plastic fracture indexes derived from ABAQUS are shown in Figure 9.

All $R_{\sigma}$ curves of WF-A have an "M" fluctuation along the length of the weld, the trend is stable, and the values are between 0.6 and 1.0. PI and RI both show a "W" fluctuation along the length of the weld, which means that there is a greater possibility of cracking at both ends of the weld than in the middle of the weld. RI slightly decreases as $l_{a}$ increases; $\mathrm{RI}$ is the highest in WF-A1. Considering the economic factors, such as material consumption, it is suggested that the length of the line $\left(l_{a}\right)$ should be $0.60-0.80$ times the width of the beam.

3.6.6. Influence of $l_{b}$. Similar to the analysis of $l_{a}, 6$ numerical simulation models are analyzed for the influence of the length $l_{b}$ of the transition section. The results of $R_{\sigma}, \mathrm{PI}$, and RI are shown in Figure 10.

All $R_{\sigma}$ curves of WF-B have an "M" fluctuation along the length of the weld, during which there is a slight decrease of $\pm 80 \mathrm{~mm}$. Compared to WF-A, the values are increased by 0.6-1.2. The overall trends in Figures 10(b) and 10(c) show that PI and RI are similar. As $l_{b}$ increases, RI decreases first and then increases. The minimum value of RI is found in WF-B3, which indicates that $l_{b}$ is too large to reduce the possibility of deformation and brittle fracture of the weld. Therefore, it is suggested that the length of the arc $\left(l_{b}\right)$ should be $0.30-0.35$ times the height of the beam.

3.6.7. Influence of $c$. Similar to the analysis of $l_{a}$ and $l_{b}, 6$ numerical models are analyzed for the analysis of $c$, whose parameters vary for WF-C. $R_{\sigma}$, PI, and RI are presented in Figure 11.

Figure 11(a) shows that the $R_{\sigma}$ curves of WF-C have an " $M$ " fluctuation along the length of the weld. Compared with WF-A and WF-B, the difference between the WF-C 

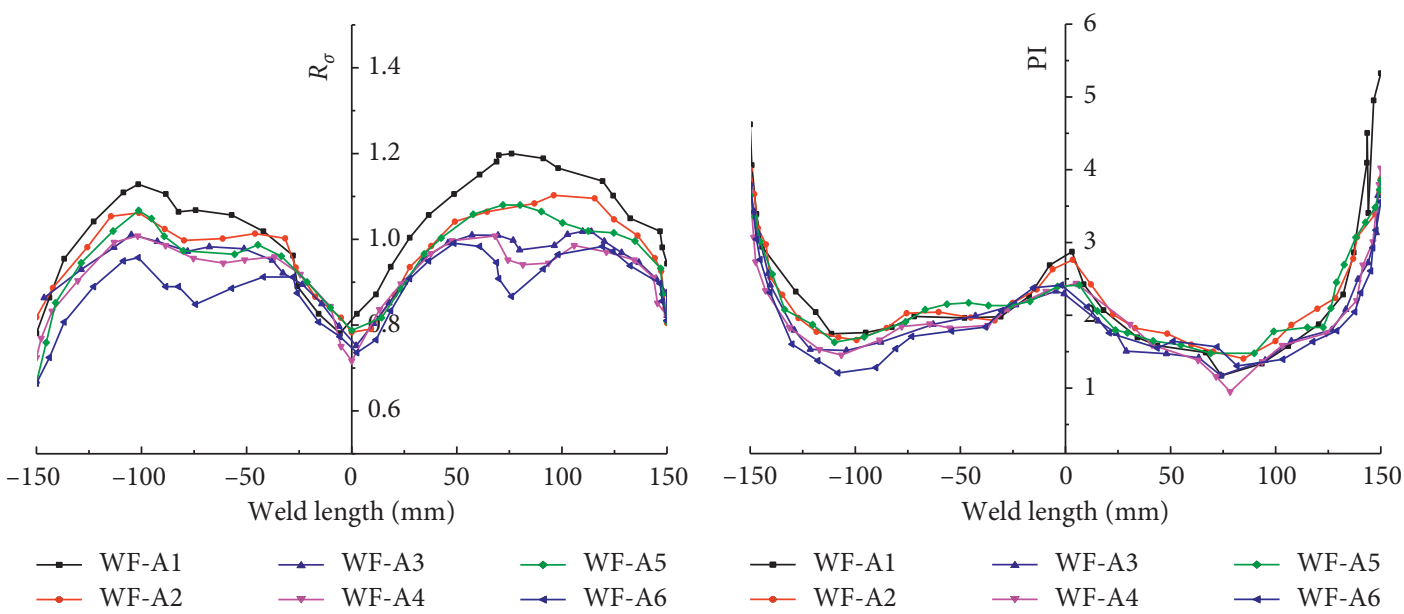

$\leftarrow$ WF-A3

- WF-A5

(a)

(b)

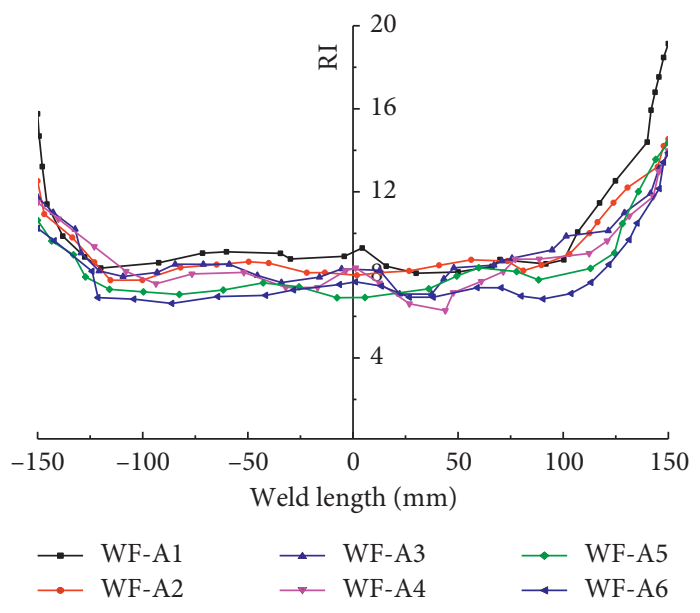

(c)

Figure 9: WF-A. (a) Triaxiality ratio. (b) Equivalent plastic strain index. (c) Cracking index.

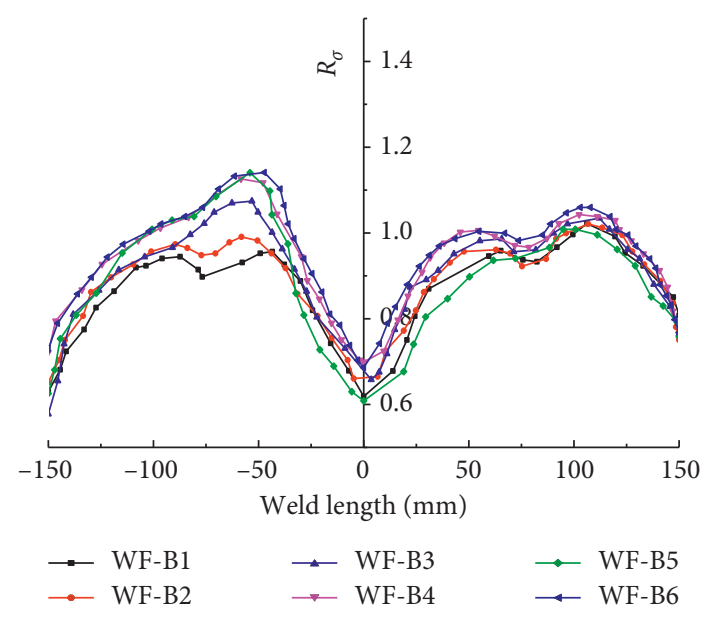

(a)

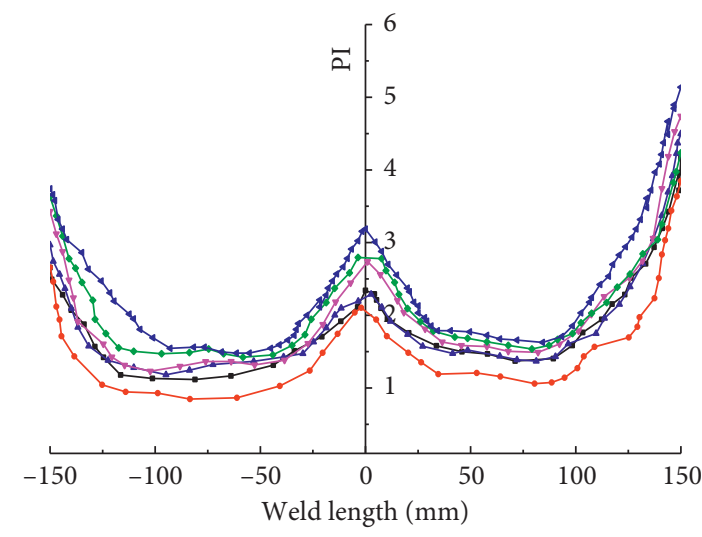

$\rightarrow$ WF-B1

$\rightarrow$ WF-B3

$\rightarrow$ WF-B5

$\because$ WF-B2

(b)

FIgURE 10: Continued. 


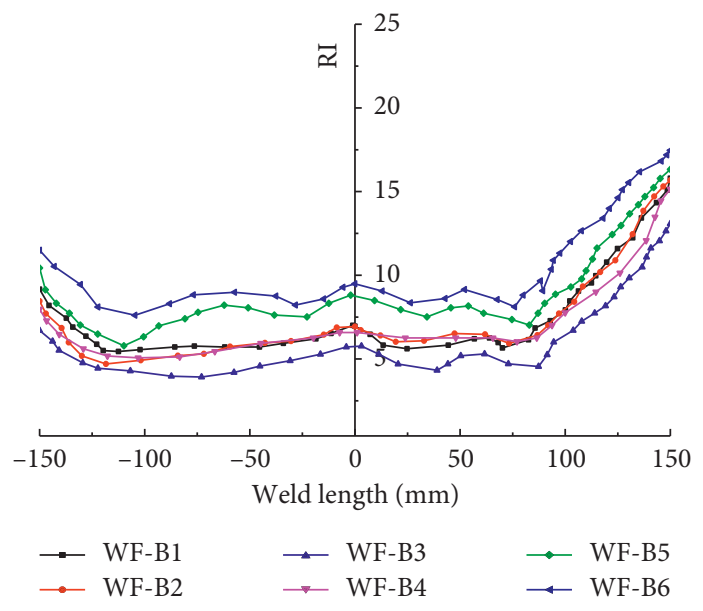

(c)

Figure 10: WF-B. (a) Triaxiality ratio. (b) Equivalent plastic strain index. (c) Cracking index.
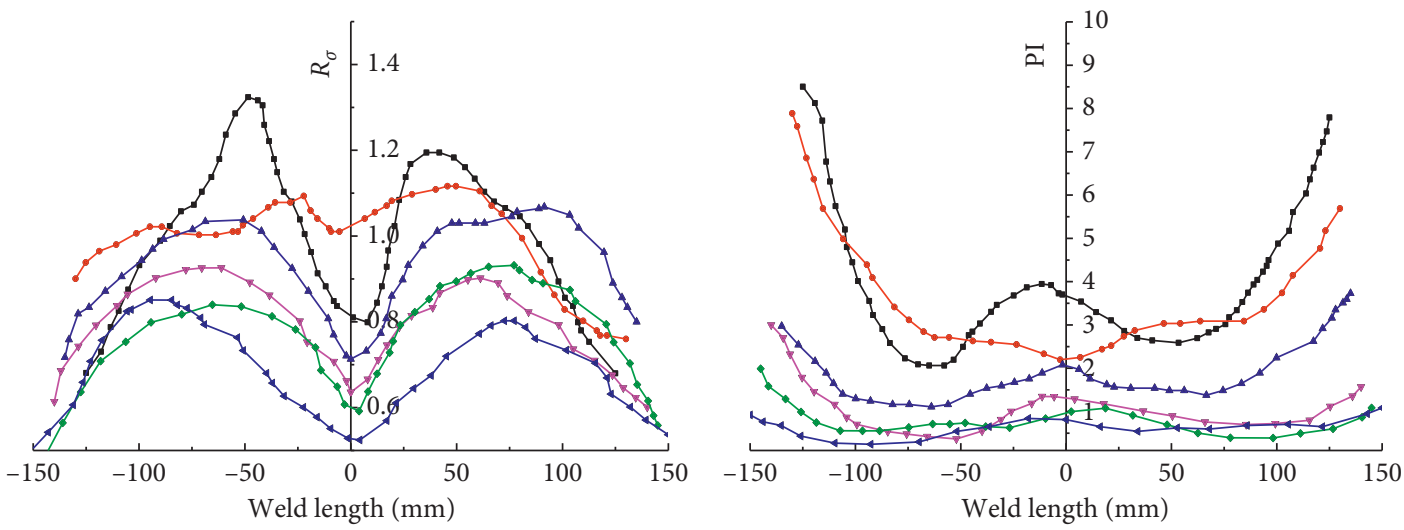

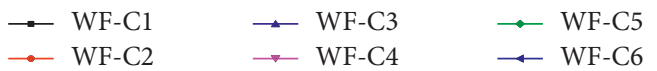

(a)

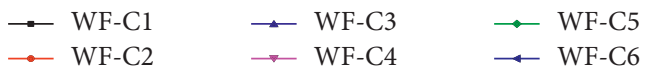

(b)

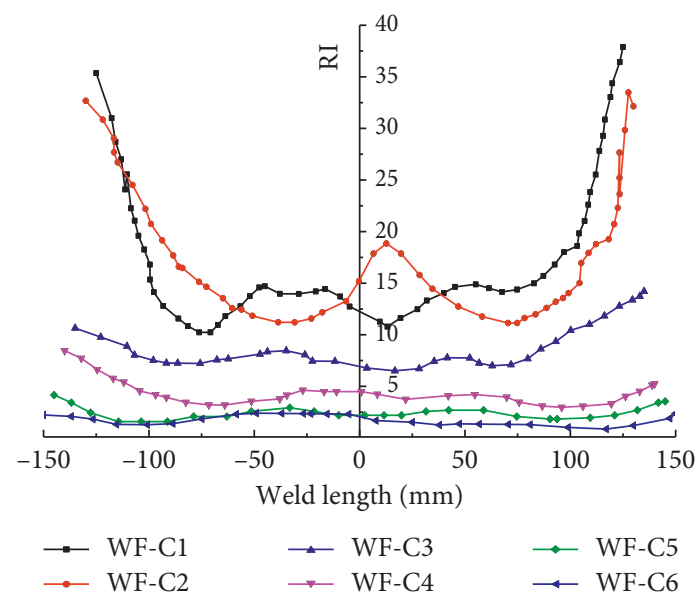

(c)

Figure 11: WF-C. (a) Triaxiality ratio. (b) Equivalent plastic strain index. (c) Cracking index. 
connections is larger, and the values gradually decrease with increasing $c$. PI and RI both show a "W" shape along the length of the weld but tend to flatten when $c$ reaches $40 \mathrm{~mm}$. As $c$ increases, RI exhibits a significant downward trend in the early stage, and the RI values of WF-C5 and WF-C6 are nearly the same. Considering the economic factors, such as material consumption, it is suggested that the width $(c)$ should be $0.20-0.25$ times the width of the beam.

\section{Conclusions}

According to the comparison of the experimental results and the finite element analysis, the following conclusions are drawn:

(1) The different lengths of the expansion of the beamcolumn connections can effectively move the plastic hinge away from the beam end. The larger the length and width of the expansion are, the higher the ultimate bearing capacity of the steel structure; however, the ductility of the material cannot be fully developed. When the length and width of the expansion are smaller, the energy dissipation capacity is stronger.

(2) According to the direction of the stress triaxiality ratio $\left(R_{\sigma}\right)$, plastic equivalent strain index (PI) and cracking index (RI) corresponding to $l_{a}, l_{b}$, and $c$ of the connections with concave arcs, it can be concluded that the ends of the weld are more likely to crack than the middle of the weld. Compared with WF-A and WF-B, WF-C has a larger difference in the index values. The width of the connections with the concave arcs has the greatest impact on the occurrence of brittle fracture.

(3) From the comprehensive analysis of the stress triaxiality ratio $\left(R_{\sigma}\right)$, plastic equivalent strain index (PI), and cracking index (RI), the optimal range of parameters for the expansion of the connections with concave arcs is given as follows: $l_{a}=(0.6-0.8) \quad b_{f} ; \quad l_{b}=(0.30-0.35) \quad h_{b}, \quad$ and $c=(0.20-0.25) b_{f}$.

\section{Data Availability}

The data used to support the findings of this study are available from the corresponding author upon request.

\section{Conflicts of Interest}

The authors declare that they have no conflicts of interest.

\section{Acknowledgments}

The authors appreciate the support of the National Science Foundation of China (51878589 and 51878590), the Production and Research Foundation of Jiangsu Province (BY2016069-01), China Postdoctoral Science Foundation (2019M651762), Six Talent Peaks Project of Jiangsu Province
(2017-JZ-038), Science and Technology Planning Project of Yangzhou City (YZ2018068), and the assistance in data processing by the postgraduate students Yake Chen and Ying Zhao, Anhui Provincial Natural Science Foundation (Project no. 1908085QA09), and Natural Science Research Project of Anhui Province (Project no. KJ2019A0591).

\section{References}

[1] P. P. Egor, Y. Y. Tzong, and P. C. Shin, "Design of steel MRF connections before and after 1994 Northridge earthquake," Engineering Structures, vol. 20, no. 12, pp. 1030-1038, 1998.

[2] D. W. Wang and W. F. Chen, "Organization and summary of discussions at the US-Japan seminar on innovations in stability concepts and methods for seismic design in structural steel," Engineering Structures, vol. 20, no. 4-6, pp. 242-248, 1998.

[3] B. Guo, Q. Gu, and F. Liu, "Experimental behavior of stiffened and unstiffened end-plate connections under cyclic loading," Journal of Structural Engineering, vol. 132, no. 9, pp. 13521357, 2006.

[4] Z. Y. Shen, Theory of Steel Structures, China Architecture \& Building Press, Beijing, China, 2005.

[5] D. T. Pachoumis, E. G. Galoussis, C. N. Kalfas, and A. D. Christitsas, "Reduced beam section moment connections subjected to cyclic loading: experimental analysis and FEM simulation," Engineering Structures, vol. 31, no. 1, pp. 216-223, 2009.

[6] D. T. Pachoumis, E. G. Galoussis, C. N. Kalfas, and I. Z. Efthimiou, "Cyclic performance of steel momentresisting connections with reduced beam sections-experimental analysis and finite element model simulation," Engineering Structures, vol. 32, no. 9, pp. 2683-2692, 2010.

[7] A. K. Swati and V. Gaurang, "Study of steel moment connection with and without reduced beam section," Case Studies in Structural Engineering, vol. 1, pp. 26-31, 2014.

[8] K. Oh, K. Lee, L. Chen, S.-B. Hong, and Y. Yang, "Seismic performance evaluation of weak axis column-tree moment connections with reduced beam section," Journal of Constructional Steel Research, vol. 105, pp. 28-38, 2015.

[9] H. Wang, S. Zhang, and J. Huo, "Tests and FE analysis for impact behavior of RBS beam-column connections of steel frames," Journal of Vibration and Shock, vol. 37, no. 11, pp. 107-114, 2018.

[10] A. A. Soliman, O. A. Ibrahim, and A. M. Ibrahim, "Effect of panel zone strength ratio on reduced beam section steel moment frame connections," Alexandria Engineering Journal, vol. 57, no. 4, pp. 3523-3533, 2018.

[11] X. Zhang, S. Zheng, and X. Zhao, "Seismic performance of steel beam-to-column moment connections with different structural forms," Journal of Constructional Steel Research, vol. 158, pp. 130-142, 2019.

[12] M. M. Nia and S. Moradi, "Effects of design factors on the cyclic response of sloped RBS moment connections," Engineering Structures, vol. 207, Article ID 110228, 2020.

[13] L. Lu, L. Wang, Y. Xu, and H. Zhang, "Finite element analysis on hysteretic behavior of joint with side-plate reinforced beam flange weak-axis connection of steel frames," Xi'an University of Architecture \& Technology, vol. 49, no. 5, pp. 646-653, 2017.

[14] Y. Wang, P. Gao, Y. Yu, and Y. Wang, "Experimental study on beam-to-column connections with beam-end horizontal haunch of steel frame under low cyclic loading," Journal of Building Structures, vol. 31, no. 4, pp. 94-101, 2010. 
[15] L. Yang and H. Chen, "Mechanical performance of beamcolumn joint with widened beam flange," Shenyang University of Technology, vol. 39, no. 4, pp. 459-463, 2017.

[16] Z. Wang, Y. Liu, R. Wang, R. Cao, and C. Mao, "Finite element study on residual stress and strain of strengthen connection," Journal of Qingdao University of Technology, vol. 39, no. 1, pp. 1-7, 2018.

[17] Y. Tian, M. Liu, Z. Jia, and Y. Dai, "Study on mechanical behavior and optimization of prefabricated square column H-beam outer-shell joint," Mechanics of Advanced Materials and Structures, vol. 27, no. 5, pp. 409-416, 2020.

[18] H. Ma, J. Wang, E. M. Lui, Z. Wan, and K. Wang, "Experimental study of the behavior of beam-column connections with expanded beam flanges," Steel and Composite Structures, vol. 31, pp. 319-327, 2019.

[19] China Construction Industry Press, Standard for Design of Steel Structures 2017, China Construction Industry Press, Beijing, China, 2017.

[20] Z. Wang and H. Shi, "Effect of the stress triaxiality on the ductile fracture," Chinese Journal of Materials Research, vol. 21, pp. 170-176, 2007.

[21] C. Mao, J. Ricles, L.-W. Lu, and J. Fisher, "Effect of local details on ductility of welded moment connections," Journal of Structural Engineering, vol. 127, no. 9, pp. 1036-1044, 2001.

[22] J. W. Hancock and A. C. MacKenzie, "On the mechanisms of ductile failure in high-strength steels subjected to multi-axial stress-states," Journal of the Mechanics and Physics of Solids, vol. 24, no. 2-3, pp. 147-160, 1976.

[23] H. Ma, Y. Zhao, Z. Wang, and Y. Chen, "Hysteretic behavior analysis of new beam-column connections with expanded flange of steel frame," Journal of Yangzhou University, vol. 20, no. 4-6, pp. 242-248, 2018.

[24] ABAQUS, Standard User Subroutines Reference Manual, The Pennsylvania State University, Philadelphia, PA, USA, 1998.

[25] K. Amar, Introduction to Finite Element Analysis Using $M A T L A B$ and ABAQUS, Taylor \& Francis Group, Boca Raton, FL, USA, 2013.

[26] Z. Zhuang, X. You, J. Liao, S. Cen, X. Shen, and M. Liang, Finite Element Analysis and Application Based on ABAQUS, Tsinghua University Press, Beijing, China, 2009, in Chinese.

[27] R. Tartaglia, M. D'Aniello, M. Zimbru, and R. Landolfo, "Finite element simulations on the ultimate response of extended stiffened end-plate joints," Steel and Composite Structures, vol. 27, no. 6, pp. 727-745, 2018.

[28] Federal Emergency Management Agency, Recommended Seismic Design Criteria for New Steel Moment-Frame Buildings, FEMA-350, SAC Joint Venture, Richmond, VA, USA, 2000.

[29] J. Xiong, "Research on the damage behavior and calculation model of welded connections in steel frames under earthquakes," Ph.D. thesis, Tsinghua University, Beijing, China, 2011.

[30] M. S. Ghobadi, M. Ghassemieh, and A. Mazroi, "Seismic performance of ductile welded connections using T-stiffener," Journal of Construction Steel Research, vol. 65, no. 4, pp. 766-775, 2009.

[31] L. Zhu, "Analysis on the effectiveness of stress triaxial as fracture parameter," Ph.D. thesis, Xi'an University of Technology, Xi'an, China, 2014.

[32] C. Zheng, L. Zhou, and K. Zhang, "Meso-mechanics of metal toughness failure and its application," Ph.D. thesis, National Defense Industry Press, Beijing, China, 1995.
[33] S. EI-Tawil, T. Mikesell, and S. K. Kunnath, "Effect of local details and yield ratio on behavior of FR steel connections," Engineering Structures, vol. 126, no. 11, pp. 79-87, 2000.

[34] J. W. Hancock and A. C. MacKenzie, "On the mechanisms of ductile failure in high strength steel subject to multi-axial stress-states," Journal of the Mechanics and Physics of Solids, vol. 24, pp. 147-169, 1976. 